Advances in Intelligent Systems and Computing 485

Francisco Rebelo

Marcelo Soares Editors

Advances in

Ergonomics in

Design

Proceedings of the AHFE 2016

International Conference on

Ergonomics in Design, July 27-31,

2016, Walt Disney World ${ }^{\circledR}$, Florida,

USA

粤 Springer 


\section{Advances in Intelligent Systems and Computing}

Volume 485

Series editor

Janusz Kacprzyk, Polish Academy of Sciences, Warsaw, Poland

e-mail: kacprzyk@ibspan.waw.pl 


\section{About this Series}

The series "Advances in Intelligent Systems and Computing" contains publications on theory, applications, and design methods of Intelligent Systems and Intelligent Computing. Virtually all disciplines such as engineering, natural sciences, computer and information science, ICT, economics, business, e-commerce, environment, healthcare, life science are covered. The list of topics spans all the areas of modern intelligent systems and computing.

The publications within "Advances in Intelligent Systems and Computing" are primarily textbooks and proceedings of important conferences, symposia and congresses. They cover significant recent developments in the field, both of a foundational and applicable character. An important characteristic feature of the series is the short publication time and world-wide distribution. This permits a rapid and broad dissemination of research results.

\section{Advisory Board}

Chairman

Nikhil R. Pal, Indian Statistical Institute, Kolkata, India

e-mail: nikhil@isical.ac.in

Members

Rafael Bello, Universidad Central "Marta Abreu" de Las Villas, Santa Clara, Cuba e-mail: rbellop@uclv.edu.cu

Emilio S. Corchado, University of Salamanca, Salamanca, Spain

e-mail: escorchado@usal.es

Hani Hagras, University of Essex, Colchester, UK

e-mail: hani@essex.ac.uk

László T. Kóczy, Széchenyi István University, Győr, Hungary

e-mail: koczy@sze.hu

Vladik Kreinovich, University of Texas at El Paso, El Paso, USA

e-mail: vladik@utep.edu

Chin-Teng Lin, National Chiao Tung University, Hsinchu, Taiwan

e-mail: ctlin@mail.nctu.edu.tw

Jie Lu, University of Technology, Sydney, Australia

e-mail: Jie.Lu@uts.edu.au

Patricia Melin, Tijuana Institute of Technology, Tijuana, Mexico

e-mail: epmelin@hafsamx.org

Nadia Nedjah, State University of Rio de Janeiro, Rio de Janeiro, Brazil

e-mail: nadia@eng.uerj.br

Ngoc Thanh Nguyen, Wroclaw University of Technology, Wroclaw, Poland

e-mail: Ngoc-Thanh.Nguyen@pwr.edu.pl

Jun Wang, The Chinese University of Hong Kong, Shatin, Hong Kong

e-mail: jwang@mae.cuhk.edu.hk

More information about this series at http://www.springer.com/series/11156 
Francisco Rebelo $\cdot$ Marcelo Soares

Editors

\section{Advances in Ergonomics in Design}

Proceedings of the AHFE 2016 International Conference on Ergonomics in Design, July 27-31, 2016, Walt Disney World ${ }^{\circledR}$, Florida, USA

第 Springer 


\section{Editors}

Francisco Rebelo

Universidade de Lisboa

Lisbon

Portugal
Marcelo Soares

Federal University of Pernambuco

Recife

Brazil

ISSN 2194-5357

ISSN 2194-5365 (electronic)

Advances in Intelligent Systems and Computing

ISBN 978-3-319-41982-4

ISBN 978-3-319-41983-1 (eBook)

DOI 10.1007/978-3-319-41983-1

\section{Library of Congress Control Number: 2016944167}

(C) Springer International Publishing Switzerland 2016

This work is subject to copyright. All rights are reserved by the Publisher, whether the whole or part of the material is concerned, specifically the rights of translation, reprinting, reuse of illustrations, recitation, broadcasting, reproduction on microfilms or in any other physical way, and transmission or information storage and retrieval, electronic adaptation, computer software, or by similar or dissimilar methodology now known or hereafter developed.

The use of general descriptive names, registered names, trademarks, service marks, etc. in this publication does not imply, even in the absence of a specific statement, that such names are exempt from the relevant protective laws and regulations and therefore free for general use.

The publisher, the authors and the editors are safe to assume that the advice and information in this book are believed to be true and accurate at the date of publication. Neither the publisher nor the authors or the editors give a warranty, express or implied, with respect to the material contained herein or for any errors or omissions that may have been made.

Printed on acid-free paper

This Springer imprint is published by Springer Nature

The registered company is Springer International Publishing AG Switzerland 


\title{
Effects of Different Body Postures on Anthropometric Measures
}

\author{
Sara Bragança, Pedro Arezes, Miguel Carvalho and Susan Ashdown
}

\begin{abstract}
The shape and size of the human body is affected by the posture adopted in order to perform various activities. The human body is constantly changing and adapting to the movements executed in everyday life. As such, knowledge about the body changes that occur with the adoption of different postures is essential. Besides the obvious adverse health effects caused by spending long periods of time in certain postures, the adopted posture may influence people's interaction even with the simplest items such as clothing. For all these reasons, being able to determine the anthropometric changes related to different work postures is very important to occupational ergonomics. The main objective of this paper is to identify and quantify the body changes that occur with each of the postures adopted.
\end{abstract}

Keywords Anthropometry - Working postures - Human body • Variations

\section{Introduction}

Fashion designers have to rely on anthropometric studies that represent target populations, considering their standing and static position. However, it can be difficult to find appropriate anthropometric data and the most frequent situation is to have anthropometric data that has been collected from populations that are

\footnotetext{
S. Bragança $(\bowtie) \cdot$ P. Arezes $\cdot$ M. Carvalho

University of Minho, Guimarães, Portugal

e-mail: saraabraganca@gmail.com

P. Arezes

e-mail: parezes@dps.uminho.pt

M. Carvalho

e-mail: migcar@dps.uminho.pt

S. Ashdown

Cornell University, Ithaca, NY, USA

e-mail: spa4@cornell.edu

F. Rebelo and M. Soares (eds.), Advances in Ergonomics in Design,

Advances in Intelligent Systems and Computing 485,

DOI 10.1007/978-3-319-41983-1_28
} 
noticeably different from the target populations [1]. In many countries the products are designed according to the extensive data available for military populations.

Unlike other consumer products, with dimensions based on combined anthropometric data from men and women, data needed for clothing design is very sensitive.

Body shapes and sizes vary according to many factors as gender, age and culture in ways that have an impact on clothing fit.

Additionally, anthropometric surveys are usually different in terms of population size, age groups, procedures used and, time of the measurements [2]. All these aspects can lead to a mismatch in the dimensions of the product and the user.

Some researchers have tried to determine the changes in shape and size of the human body that occur according to the posture adopted. For example, Carvalho et al. [3] performed a comparative anatomical study between the standing and sitting positions, analyzing the dimensional and postural alterations of the human body when sitting, in which they identified:

- Shrinkage of the trunk;

- Volume increase in the abdominal region;

- Variation in height, volume and inclination of the waist;

- Broadening of the hips;

- Redistribution of the muscular mass in the thighs;

- Increase of upper-back bending;

- Modification of the angular position of the elbow;

- Increase of the leg frontal length caused by the flexion of the knees.

Most of these postures can become uncomfortable for workers, especially when the clothes they wear are not adequate and cannot be adapted to the challenges of the tasks to be performed. As such, some of these challenges can be mitigated when wearing appropriate clothing, preventing health issues and increasing perceived comfort.

Frequently some discomfort in clothing can be felt with movement or when dynamic postures are assumed. When the body moves the dimensions change, for example the increase of the length on one side of a bending joint and the decrease of the length on the other side [4]. If the clothing does not increase in dimension over a bending joint, or binds where body dimensions decrease, it will restrict movement or intensify its difficulty creating discomfort.

Several studies evaluated the impact of the body changes in the clothing fit and comfort. Lotens [5] determined the ease needed in clothing for seven extreme postures. Cichocka et al. [6] quantified body changes with movement for the shoulders, buttocks, arms, legs, elbows and knees. Aldrich et al. [7] described garment distortions related to body movements. Lee and Ashdown compared [8] the variations in upper body measurements for three active postures. Choi and Ashdown [9, 10] calculated the differences in body measurements between standing and sitting postures, finding an increase of waist girth by $8 \%$; an increase of hip 
girth by $7 \%$; a decrease of crotch girth by $16 \%$ and an increase of center leg length by $10 \%$ when in the sitting posture.

According to Cichocka et al. [11] developing a garment may be one of the most difficult problems in the field of textile engineering, and consequently, before designing a garment adapted to the human body, it is imperative to have an intimate knowledge of its morphology in order to create the final style successfully.

In this paper the anthropometric measurements of 50 workers were collected in different postures. The purpose of this was to quantify the variations that occur in the human body when different postures are adopted. Moreover, it allowed understanding how this variability will affect the clothing design in order to maximize fit and comfort.

\section{Materials and Methods}

Fifty participants volunteered to take part in this study; 12 of them were females and 38 were males. This sample had an average age of $36.49 \pm 11.39$ years old, an average height of $170.86 \pm 69.3 \mathrm{~cm}$ and an average weight of $71.30 \pm 10.70 \mathrm{~kg}$.

The participants worked in four different companies/institutions - one research centre, one software development company, one industrial company and one university. A formal contact was established with the companies, inviting them to participate in the study. The participation in this study was voluntary and the management board of the company selected the participants. When contacted, the participants were informed of the detailed procedures and requirements of the test.

The data collection was performed by one certified anthropometrist that collected all the anthropometric data, using traditional anthropometry techniques (with a regular measuring tape and a Harpenden anthropometer). A total of 25 measurements were collected, representing the basic body measurements that are needed for the design of the base patterns [12]. Some of the measurements were collected in different postures to try to identify the modifications on the body that occur when people are not on the stationary standing position. These postures were selected to include postures where more significant differences were expected to be found and, as shown in Fig. 1, were the following:

- P1: stationary standing with arms to the sides;

- P2: sitting with the knees bent at $90^{\circ}$ and feet touching the ground;

- P3: standing with arms to the front parallel to the ground;

- P4: standing with arms up in a 180-degree angle with the trunk;

- P5: standing with arms to the sides in a 90-degree angle with the trunk.

The anthropometric measurements collected were divided in two categories: static (the ones collected in posture P1 and posture P2) and dynamic (the ones collected in the other postures, P3, P4 and P5)-Table 1.

Figure 2 shows a representation of the measurements in the human body. 


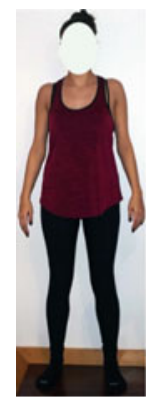

P1

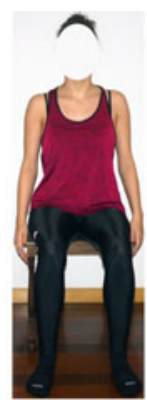

P2

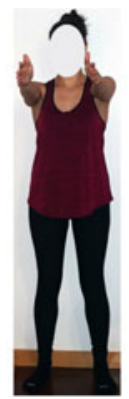

P3

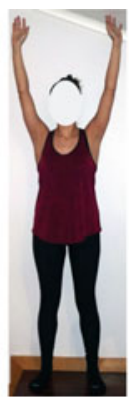

P4

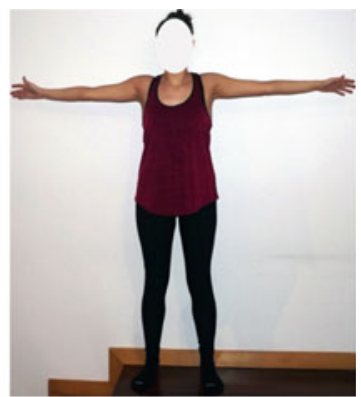

P5

Fig. 1 Postures in which the measurements were taken (from P1 to P5)

Table 1 Measurements collected for the study

\begin{tabular}{|c|c|c|c|c|c|c|c|}
\hline Type & ID & Measurement & Posture & Type & ID & Measurement & Posture \\
\hline \multirow[t]{17}{*}{ Static } & 1 & $\begin{array}{l}\text { Neck base } \\
\text { girth }\end{array}$ & P1 & \multirow[t]{17}{*}{ Dynamic } & 18 & Waist girth & $\mathrm{P} 1, \mathrm{P} 2$ \\
\hline & 2 & Chest girth & P1 & & 19 & $\begin{array}{l}\text { Abdomen } \\
\text { girth }\end{array}$ & $\mathrm{P} 1, \mathrm{P} 2$ \\
\hline & 3 & Knee girth & P1 & & 20 & Hip girth & $\mathrm{P} 1, \mathrm{P} 2$ \\
\hline & 4 & Calf girth & P1 & & 21 & Thigh girth & $\mathrm{P} 1, \mathrm{P} 2$ \\
\hline & 5 & Ankle girth & P1 & & 22 & Leg length & $\mathrm{P} 1, \mathrm{P} 2$ \\
\hline & 6 & Arm girth & P1 & & 23 & Crotch length & $\mathrm{P} 1, \mathrm{P} 2$ \\
\hline & 7 & $\begin{array}{l}\text { Forearm } \\
\text { girth }\end{array}$ & P1 & & 24 & $\begin{array}{l}\text { Across chest } \\
\text { length }\end{array}$ & $\begin{array}{l}\text { P1, P3, } \\
\text { P4, P5 }\end{array}$ \\
\hline & 8 & Arm length & P1 & & 25 & $\begin{array}{l}\text { Across back } \\
\text { length }\end{array}$ & $\begin{array}{l}\text { P1, P3, } \\
\text { P4, P5 }\end{array}$ \\
\hline & 9 & $\begin{array}{l}\text { Crotch length } \\
\text { back }\end{array}$ & $\mathrm{P} 2$ & & & & \\
\hline & 10 & $\begin{array}{l}\text { Crotch length } \\
\text { front }\end{array}$ & $\mathrm{P} 2$ & & & & \\
\hline & 11 & $\begin{array}{l}\text { Upper leg } \\
\text { length }\end{array}$ & $\mathrm{P} 2$ & & & & \\
\hline & 12 & $\begin{array}{l}\text { Lower leg } \\
\text { length }\end{array}$ & P1 & & & & \\
\hline & 13 & Knee height & P1 & & & & \\
\hline & 14 & Waist height & P1 & & & & \\
\hline & 15 & $\begin{array}{l}\text { Shoulder } \\
\text { height }\end{array}$ & P1 & & & & \\
\hline & 16 & Stature & P1 & & & & \\
\hline & 17 & Weight & P1 & & & & \\
\hline
\end{tabular}




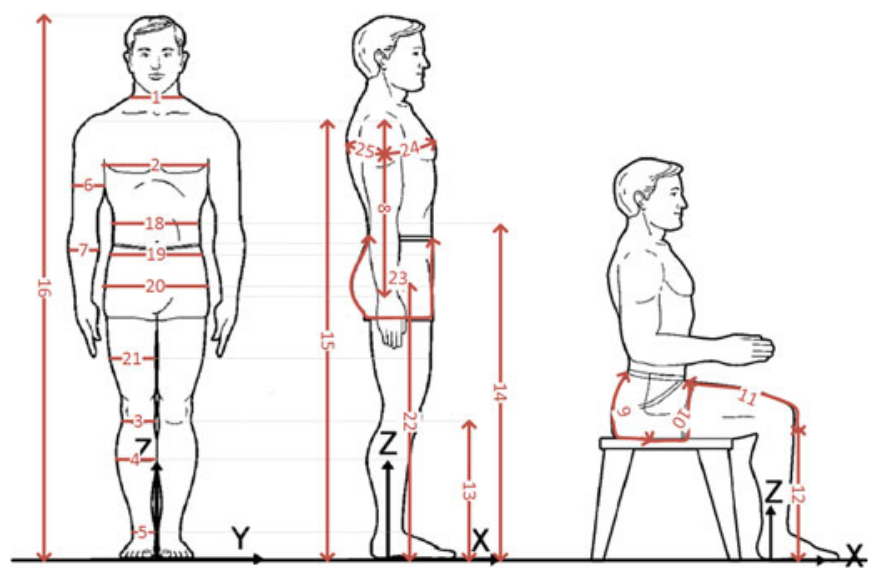

Fig. 2 Representation of the measurements taken on the human body

Regarding the analysis of the data, descriptive statistics were calculated (mean and standard deviation), as well as the mean differences registered between the measurements collected in the static and in the dynamic postures. To analyze the meaning of these differences, a paired samples t-test was used. The significance level was set at $0.05(\alpha=0.05)$, meaning that body measurements with $p$ values lower than 0.05 were considered to have significant difference between postures.

\section{Results and Discussion}

Table 2 shows the means, standard deviations, minimum and maximum values for all measurements collected with all the 50 participants.

The results obtained demonstrate that there is a difference in the measurements according to the posture adopted. Table 3 displays the mean difference registered (both in $\mathrm{mm}$ as in percentage) when the posture changes. Positive values imply that the body measurement increases from P1 to the other posture (P2, P3, P4 or P5) while negative values indicate that the body measurement decreases with the posture.

As it can be seen, there are some measurements with considerable differences according to the posture adopted. For example, raising the arms upwards makes the across chest length decrease about $16 \%$, when compared to the regular static standing posture. As all the body measurements are related to one another, consequently, the across back length increases about $5 \%$.

Most of the measurements had a large variation. However, there are other measurements that only change slightly, as is the case of the leg length, which only increases about $1 \%$. 
Table 2 Mean, standard deviation, minimum and maximum values of the body measurements considered (in $\mathrm{mm}$ )

\begin{tabular}{|c|c|c|c|c|}
\hline Measurement & Mean & Standard deviation & Maximum & Minimum \\
\hline Neck base girth & 396.2 & 25.2 & 457.0 & 338.9 \\
\hline Chest girth & 994.4 & 86.2 & 1317.1 & 820.5 \\
\hline Knee girth & 359.7 & 24.2 & 432.4 & 307.5 \\
\hline Calf girth & 368.5 & 26.3 & 444.5 & 323.0 \\
\hline Ankle girth & 243.3 & 24.1 & 331.6 & 210.0 \\
\hline Arm girth & 306.1 & 34.4 & 397.0 & 230.0 \\
\hline Forearm girth & 253.0 & 32.3 & 350.0 & 182.6 \\
\hline Arm length & 541.4 & 38.2 & 650.0 & 473.5 \\
\hline Crotch length back & 422.9 & 78.7 & 550.0 & 347.4 \\
\hline Crotch length front & 250.5 & 59.5 & 395.0 & 202.6 \\
\hline Upper leg length & 460.4 & 40.2 & 555.0 & 390.0 \\
\hline Lower leg length & 431.8 & 90.1 & 550.0 & 250.0 \\
\hline Knee height & 539.9 & 122.3 & 744.0 & 291.8 \\
\hline Waist height & 1168.3 & 364.5 & 3610.0 & 957.2 \\
\hline Shoulder height & 1415.6 & 87.5 & 1593.0 & 1248.7 \\
\hline Stature & 1708.6 & 69.3 & 1830.0 & 1560.0 \\
\hline Weight & 713.0 & 107.0 & 1003.0 & 518.0 \\
\hline Waist girth P1 & 831.5 & 94.3 & 1087.0 & 678.0 \\
\hline Waist girth $\mathrm{P} 2$ & 864.9 & 100.3 & 1161.0 & 706.0 \\
\hline Abdomen girth P1 & 918.3 & 99.6 & 1194.8 & 762.0 \\
\hline Abdomen girth P2 & 984.8 & 136.9 & 1331.2 & 765.0 \\
\hline Hip girth P1 & 982.5 & 65.1 & 1169.0 & 856.0 \\
\hline Hip girth P2 & 1020.2 & 66.6 & 1232.0 & 907.0 \\
\hline Thigh girth $\mathrm{P} 1$ & 488.3 & 41.4 & 607.0 & 430.0 \\
\hline Thigh girth P2 & 507.3 & 44.9 & 605.0 & 405.0 \\
\hline Leg length P1 & 891.3 & 117.2 & 1075.0 & 670.0 \\
\hline Leg length P2 & 894.4 & 87.8 & 1040.0 & 740.0 \\
\hline Crotch length P1 & 708.6 & 91.3 & 930.0 & 530.0 \\
\hline Crotch length P2 & 668.5 & 129.9 & 880.0 & 500.0 \\
\hline Across chest length P1 & 443.8 & 55.4 & 553.0 & 348.0 \\
\hline Across chest length P3 & 393.8 & 60.5 & 516.0 & 292.0 \\
\hline Across chest length $\mathrm{P} 4$ & 379.6 & 60.0 & 503.0 & 295.0 \\
\hline Across chest length P5 & 424.6 & 55.0 & 528.0 & 315.0 \\
\hline Across back length P1 & 503.4 & 55.5 & 600.0 & 369.0 \\
\hline Across back length P3 & 533.3 & 70.7 & 750.0 & 380.0 \\
\hline Across back length P4 & 528.2 & 70.1 & 660.0 & 338.0 \\
\hline Across back length P5 & 497.6 & 55.5 & 590.0 & 373.0 \\
\hline
\end{tabular}


Table 3 Mean differences between body measurements in different postures

\begin{tabular}{|c|c|c|c|}
\hline Measurement & \multicolumn{3}{|c|}{ Mean difference in $\mathrm{mm}$ (and percentage \%) } \\
\hline Waist girth & \multicolumn{3}{|l|}{$+33.4(+4.04 \%)^{\mathrm{a}}$} \\
\hline Abdominal girth & \multicolumn{3}{|l|}{$+63.9(+6.96 \%)^{\mathrm{a}}$} \\
\hline Hip girth & \multicolumn{3}{|l|}{$+37.7(+3.86 \%)^{\mathrm{a}}$} \\
\hline Thigh girth & \multicolumn{3}{|l|}{$+19.0(+4.05 \%)^{\mathrm{a}}$} \\
\hline Leg length & \multicolumn{3}{|l|}{$+39.2(+0.86 \%)^{\mathrm{a}}$} \\
\hline Crotch length & \multicolumn{3}{|l|}{$-26.5(-5.57 \%)^{\mathrm{a}}$} \\
\hline Across chest length & $-50.1(-11.37 \%)^{b}$ & $-64.2(-15.83 \%)^{\mathrm{c}}$ & $-19.2(-4.17 \%)^{\mathrm{d}}$ \\
\hline Across back length & $30.0(+5.91 \%)^{\mathrm{b}}$ & $24.8(+4.82 \%)^{\mathrm{c}}$ & $-5.8(-1.09 \%)^{\mathrm{d}}$ \\
\hline
\end{tabular}

${ }^{\text {a }}$ 1 compared to $\mathrm{P} 2$

${ }^{\mathrm{b}} \mathrm{P} 3$ compared to $\mathrm{P} 1$

${ }^{\mathrm{c}} \mathrm{P} 4$ compared to $\mathrm{P} 1$

${ }^{\mathrm{d}} \mathrm{P} 5$ compared to $\mathrm{P} 1$

Table 4 Results of the paired-samples t-test

\begin{tabular}{|c|c|c|c|c|}
\hline \multicolumn{2}{|c|}{ Measurement } & \multirow{2}{*}{$\begin{array}{l}\mathrm{t} \\
-9.643\end{array}$} & \multirow{2}{*}{$\begin{array}{l}\text { df } \\
49\end{array}$} & \multirow{2}{*}{\begin{tabular}{|l|} 
Sig. (2-tailed) \\
$<0.001 *$
\end{tabular}} \\
\hline Pair 1 & Waist girth $\mathrm{P} 1$ - waist girth $\mathrm{P} 2$ & & & \\
\hline Pair 2 & Abdomen girth $\mathrm{P} 1$ - abdomen girth $\mathrm{P} 2$ & -9.088 & 47 & $<0.001 *$ \\
\hline Pair 3 & Hip girth $\mathrm{P} 1$ - hip girth $\mathrm{P} 2$ & -14.481 & 49 & $<0.001 *$ \\
\hline Pair 4 & Thigh girth $\mathrm{P} 1$ - thigh girth $\mathrm{P} 2$ & -4.307 & 49 & $<0.001 *$ \\
\hline Pair 5 & Leg length P1-leg length P2 & -0.496 & 49 & $0.622 * *$ \\
\hline Pair 6 & Crotch length $\mathrm{P} 1$ - crotch length $\mathrm{P} 2$ & 2.761 & 49 & $0.008 * *$ \\
\hline Pair 7 & Chest P1 — chest P3 & 12.404 & 49 & $<0.001 *$ \\
\hline Pair 8 & Chest P1—chest P4 & 9.452 & 49 & $<0.001 *$ \\
\hline Pair 9 & Chest P1—chest P5 & 4.774 & 49 & $<0.001 *$ \\
\hline Pair 10 & Back P1-back P3 & -5.677 & 49 & $<0.001 *$ \\
\hline Pair 11 & Back P1-back p4 & -5.229 & 49 & $<0.001 *$ \\
\hline Pair 12 & Back P1-back P5 & 2.130 & 49 & $0.038 * *$ \\
\hline
\end{tabular}

$* p<0.05$ statistically significant difference; $* * p>0.05$ no statistically significant difference

The results of the paired samples t-test (shown in Table 4) demonstrated that for the majority of the comparisons there is a statistically significant difference $(p<0.05)$ between the measurements.

Amongst all the pairs, the only ones that did not have a statistically significant difference were the leg length, the crotch length and the across back length in P1 and P5. However, it should be noted that the crotch length pair showed a value very close to 0.05 . This means that if the significance level was set at a higher value (e.g. 0.09 rather than 0.05 ) the difference between this pair of measurements would be considered to have a statistically significant difference.

A previous study, conducted by the authors to the same sample by applying questionnaires, revealed to be in accordance with the data obtained from the anthropometric measurements [13]. The areas pointed-out as areas of limitation of 
movements in the questionnaire were the ones measured in the study in distinct postures-sleeves; armholes; shoulders; chest and back, evaluated through the across chest length and across back length; waist evaluated through the waist girth; hip evaluated through the hip girth; thighs evaluated through the thigh girth; legs evaluated through the leg length. Additionally, all these areas presented a considerable variation with the change in the posture adopted. These changes are even visible to the naked eye, as demonstrated in Figs. 3 and 4, where it is clear that when the posture changes the body shape and size varies accordingly.

From standing to sitting, i.e., from P1 to P2, the variations occur mostly in the lower part of the body. These variations include: (i) the increase in the breadth of the hip and thighs due to the pressure exerted by the stool; (ii) the reduction in the spinal column's arch due to the rotation of the hip forewords; (iii) the augmentation of the protuberance in the abdominal region; and (iv) the increase in the leg length in the front of the leg over the knee caused by the bending of the knees.

When changing from P1 to P3 the variations occur solely in the upper part of the body. Some of these variations include: (i) the increase in the shoulder height;
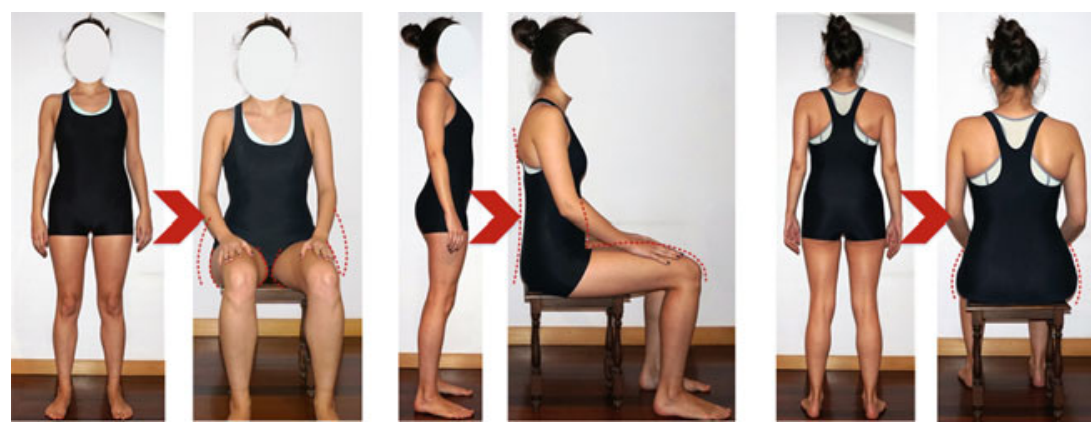

Fig. 3 Changes in the body that occur from standing to sitting
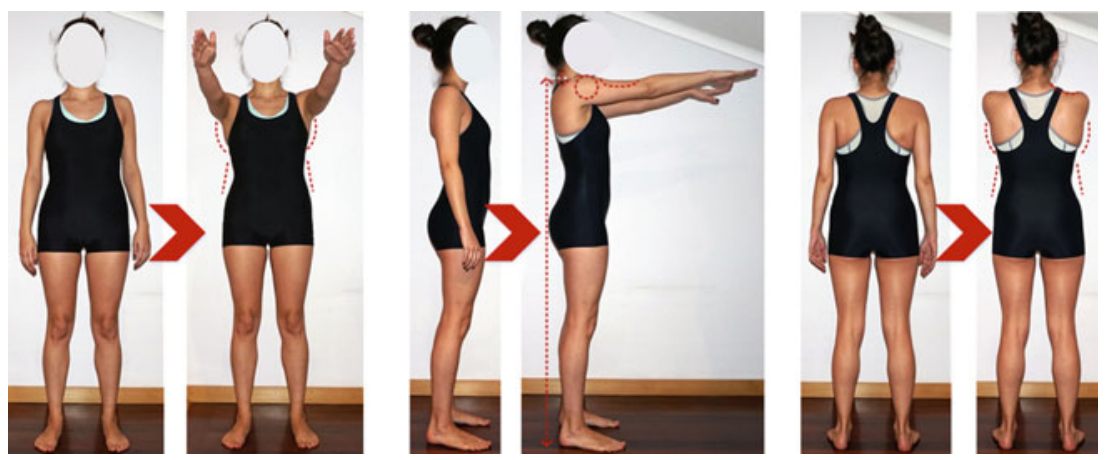

Fig. 4 Changes in the body that occur from P1 to P3 
(ii) the reduction of the waist curvature (more evident in women); (iii) the decrease in the chest breadth; (iv) the intensification of tension in the shoulders and arms regions (especially in the deltoid, biceps and trapezius muscles); and (v) the increase in the back breadth.

In fact, all the measurements in this study, except the leg length, presented a statically significant difference when the posture changes. This makes it easy to understand that the feeling of comfort with clothing that users get is not the same when they are in different dynamic postures. Despite the variation in the measurements was almost all below $10 \%$, it is still a considerable difference that may have a great impact on garment fit and comfort.

\section{Conclusions}

People are becoming more and more sedentary but there is still the need to perform some movements and adopt some postures during leisure and work activities that may be negatively influenced by clothing. Some examples of those types of postures are the ones presented in this study, which proved to have quite a meaningful impact on the anthropometric measurements and consequent fit and comfort of clothing items.

The significance of the differences quantified here can also be demonstrated with other test (e.g. measurement of compression forces exerted by clothing when in different postures), where it would be possible to see that clothes that are not designed taking in consideration the dynamic postures affect in great part the compression imposed to the user, limiting his/her movements and causing discomfort.

Acknowledgments This work is financed by FEDER funds through the Competitive Factors Operational Program (COMPETE) POCI-01-0145-FEDER-007043 and POCI-01-0145-FEDER-007136 and by national funds through FCT-Portuguese Foundation for Science and Technology, under the projects UID/CEC/00319/2013 and UID/CTM/000264.

\section{References}

1. Parkinson, M.B., Reed, M.P.: Creating virtual user populations by analysis of anthropometric data. Int. Journal of Ind. Ergon. 40(1), 106-111 (2010). http://doi.org/10.1016/j.ergon.2009. 07.003

2. Gupta, D., Gupta, D., Zakaria, N.: Anthropometry and the design and production of apparel: an overview. In: Anthropometry, Apparel Sizing and Design, pp. 34-66. Woodhead Publishing Ltd., United Kingdom (2014)

3. Carvalho, M., Duarte, F., Heinrich, D., Woltz, S.: WeAdapt: Inclusive Clothing Design Proposal for Product Development. In Include (2009) 
4. Kirk, W., Ibrahim, S.M.: Fundamental relationship of fabric extensibility to anthropometric requirements and garment performance. Text. Res. J. 36(1), 37-47 (1966). http://doi.org/10. $1177 / 004051756603600105$

5. Lotens, W.A.: Optimal design principles for clothing systems. Handbook on Clothing, Research Study Group on Biomedical Research Aspects of Military Protective Clothing, pp. 1701-1715. NATO, Brussels (1989)

6. Hatch, K.L.: Textile Science. West Publishing Co, Minneapolis (1993)

7. Aldrich, W., Smith, B., Dong, F.: Obtaining repeatability of natural extended upper body positions: its use in comparisons of the functional comfort of garments. J. Fashion Mark. Manage. Int. J. 2(4), 329-351 (1998). http://doi.org/10.1108/eb022538

8. Lee, J., Ashdown, S.P.: Upper body surface change analysis using 3-D body scanner. J. Korean Soc. Clothing Text. 29(12), 1595-1607 (2005)

9. Choi, S., Ashdown, S.P.: Application of lower body girth change analysis using 3D body scanning to pants patterns. J. Korean Soc. Clothing Text. 34(6), 955-968 (2010). http://doi. org/10.5850/JKSCT.2010.34.6.955

10. Choi, S., Ashdown, S.P.: 3D body scan analysis of dimensional change in lower body measurements for active body positions. Text. Res. J. 81(1), 81-93 (2011). http://doi.org/10. 1177/0040517510377822

11. Cichocka, A., Bruniaux, P., Frydrych, I.: 3D garment modelling-creation of a virtual mannequin of the human body. Fibres Text. Eastern Eur. (2014)

12. GUDI: Método de corte: Vestuário feminino. In Manual de Formação. Escola de Moda GUDI, Porto (2007)

13. Bragança, S., Carvalho, M., Arezes, P., Ashdown, S., Fontes, L.: Identification of preponderant factors for work-wear design. In: Proceedings of the 90th Textile Institute World Conference, Poznan, Poland, 25-28 April 2016 